\title{
THE ARKANSAS "Most CROP PER DROP” CONTEST: AN INNOVATIVE EXTENSION METHOD TO IMPROVE IRRIGATION WATER MANAGEMENT ADOPTION
}

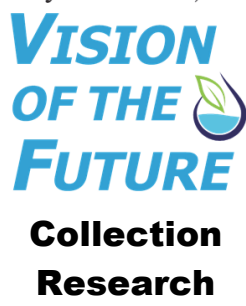

\author{
C. G. Henry, L. J. Krutz, R. Mane, G. D. Simpson
}

Research

\section{HighLIGHTS}

- An integrated research and Extension program promoted adoption of computerized hole selection (CHS), surge irrigation, soil moisture monitoring, and multiple inlet rice irrigation (MIRI) for surface irrigators in Arkansas.

- Using a contest design, water use efficiency (WUE) was determined for maize, soybean, and rice fields, and report cards were provided to contest participants to provide feedback on their irrigation acumen.

- The highest yielding fields did not always result in the highest WUE.

- The contest was implemented on working commercial farms in the Arkansas Delta using flowmeters and in-field crop yield checks for the purpose of promoting adoption of irrigation water management (IWM).

\begin{abstract}
The Arkansas "most crop per drop" irrigation contest is an integrated research and Extension program developed to assess water use, rainfall, and yield for the purpose of estimating water use efficiency (WUE). The irrigation contest resembles traditional yield contests, with the goal of documenting WUE and increasing adoption and awareness of irrigation water management (IWM) practices in the region. Adoption of IWM practices was greater for those who participated in the contest than their Arkansas peer average, with documented adoption increases of $33 \%$ for computerized hole selection, 28\% for surge irrigation, and 51\% for soil moisture monitoring.
\end{abstract}

Keywords. Computerized hole selection, Soil moisture monitoring, Surge irrigation.

I n 2012, faculty from the University of Arkansas and Mississippi State University identified four conservation practices that were easily adopted but under-used by irrigators in the mid-south region. The mid-south region includes Arkansas, the bootheel of Missouri, Mississippi, and Louisiana, and its irrigation water is supplied by the Mississippi River valley alluvial aquifer. The region is primarily flood and furrow irrigated. The four IWM practices identified were computerized hole selection (CHS), surge irrigation, soil moisture monitoring, and multiple inlet

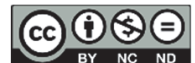
The authors have paid for open access for this article. This work is licensed under a Creative Commons AttributionNonCommercial-NoDerivatives 4.0 International License https:/creative commons.org/licenses/by-nc-nd/4.0/

Submitted for review in February 2020 as manuscript number NRES 13964; approved for publication as a Research Brief and as part of the National Irrigation Symposium 2020 Collection by the Natural Resources \& Environmental Systems Community of ASABE in June 2020.

The authors are Chris G. Henry, Associate Professor and Water Management Engineer, Department of Biological and Agricultural Engineering, University of Arkansas, Stuttgart, Arkansas; L. Jason Krutz, Director, Mississippi Water Resource Research Institute, Delta Research and Education Center, Mississippi State University, Stoneville, Mississippi; Ranjitsinh Mane, Assistant Professor, Department of Agriculture, University of Arkansas, Pine Bluff, Arkansas; Greg D. Simpson, Irrigation Program Associate, Department of Biological and Agricultural Engineering, University of Arkansas, Jonesboro, Arkansas. Corresponding author: Chris G. Henry, 2900 Hwy 130 E., Stuttgart, AR 72160; phone: 870-673-2661; e-mail: chris_henry@yahoo.com. rice irrigation (MIRI). Since that time, another practice, alternating wetting and drying (AWD), or intermittent flooding of rice paddies, has been recognized as an effective IWM practice. Demonstration programs were implemented in the region to compare the synergistic implementation of CHS, surge irrigation, and soil moisture monitoring compared to current practices. Paired fields (usually adjacent or not more than $500 \mathrm{~m}$ apart) on working commercial farms were organized across the Mississippi and Arkansas Delta regions from 2013 until 2017, primarily in furrow-irrigated soybean and maize fields (Bryant et al., 2017; Spencer et al., 2019). Portable propeller flowmeters were installed on a control field and on a field using all three IWM practices with the same soil type, same cultivar, and management. Total field crop yields were provided by farmers using certified scales.

The researchers found that implementing these practices on 20 paired furrow-irrigated soybean fields reduced water use by $21 \%$, increased water use efficiency (WUE) by $36 \%$, and reduced irrigation by $50 \%$ with no yield penalty (Bryant et al., 2017). Net returns were not appreciably different between the control and IWM fields even when the pumping cost was varied relative to well depth (5.4 to $122 \mathrm{~m}$ ) and diesel cost was between $\$ 0.46 \mathrm{~L}^{-1}$ and $\$ 1.06 \mathrm{~L}^{-1}(\mathrm{p} \geq 0.53)$. When the same study was done with 18 paired maize fields between 2013 and 2017, yields were $0.14 \mathrm{Mg} \mathrm{ha}^{-1}$ higher (p $=0.0137$ ) for the IWM fields than for the control fields (Spencer et al., 2019). Water use was $40 \%$ less on the IWM 
fields than the control fields $(\mathrm{p}=0.002)$, and irrigation WUE was $51 \%$ higher $(p=0.0062)$. Net returns were $\$ 10.12 \mathrm{ha}^{-1}$ to $\$ 15.86 \mathrm{ha}^{-1}$ higher depending on pumping depth and diesel fuel cost $(p=0.0115)$, demonstrating that investment in IWM can yield improved profitability while reducing demand on overdrawn aquifers.

MIRI is the practice of using lay-flat polyethylene irrigation pipe to distribute water evenly between rice paddies in a contour or precision-graded flooded rice field. In conventionally flooded rice fields, water cascades from one levee or paddy to the next using a gate or spill when the water depth (120 to $200 \mathrm{~mm}$ ) is high enough for water to spill over. Vories et al. (2005) documented that MIRI reduced water use and pumping time by $25 \%$. The Vories study was conducted on farms where MIRI fields were paired with conventional cascade-flooded fields, and the agronomic decisions were the same between the fields. Thus, the treatment effect was only the difference in the water management. Henry et al. (2016) studied water use reported through the University of Arkansas Rice Verification Program (RRVP). The RRVP teaches proper implementation of Extension recommendations to farmers and those who advise farmers. Henry et al. (2016) found no statistical difference in water use $(p=0.88)$ between MIRI fields and conventional cascade-flooded fields between 2003 and 2012. The authors theorized that either the fields were too small to capture the irrigation water use difference between flooded and MIRI fields, or that farmers were not managing or applying MIRI appropriately, likely guessing hole sizes.

MIRI proportions the irrigation flow for a field based on the area within each levee or paddy in the field. The gates installed in the pipe provide several different flow rates, and the flow rate is matched to the flow required for each flooded area. Thus, the water management plan includes a combination of holes, gates, and gate settings to match the flow needed for each flooded area. In 2012, it was challenging for farmers to implement MIRI because the individual levee area was not easy to determine. Without knowledge of the individual levee or paddy area, it is not possible to implement a MIRI plan. Thus, irrigators often guess at how many holes to punch and how to set the gates for each levee. While some efficiency can be gained from this, uniform flooding and distribution of water cannot be achieved. Furthermore, the main reason MIRI was not implemented was the challenge associated with determining the areas of very irregularly shaped levees.

Thus, a project was initiated in 2013 to develop a mobile app to aid irrigators in the design and implementation of MIRI (UA Irrigation Management Team, 2016, 2017). The mobile app, called Rice Irrigation, provided a means to measure levee areas and perform the calculations for MIRI planning. By 2019, farmers representing about $10 \%$ of the rice area in Arkansas were using the app to aid in the design of MIRI. Many county Extension programs have demonstrated the app for farmers.

Results from these efforts have been disseminated through county production meetings, irrigation meetings, conference meetings, and irrigation schools. However, the effectiveness of this type of demonstration program is likely reduced by the observer effect, also known as the Hawthorne effect (Roethlisberger, 1941). Individuals who are being studied may alter their responses due to their awareness of being observed. For example, in the course of IWM demonstrations, farmers using soil moisture sensors may alter the irrigation schedule for the control fields, negating the true treatment effect, and thus the true treatment differences may be understated. Additionally, because those participating in demonstration studies learn from outreach activities, treatment effects may be further reduced during a program. To combat this observational effect, demonstration programs may need to evolve or be reinvented. Quality data from onfarm demonstrations in the region are becoming more difficult to obtain. Thus, while considerable work has been published (Bryant et al., 2017; Spencer et al. 2019), successfully continuing this type of Extension program is becoming more difficult. Additional challenges often plague on-farm demonstrations, including variety and fertility differences, burst pipes, planting date differences, as well as animal damage that is not discovered until the end of the season. Additionally, on several occasions, harvest data were lost or not provided. On average, about half of all on-farm demonstration comparisons were abandoned for a variety of reasons because the treatment effect was not properly applied or the data quality was poor.

\section{Materials AND Methods}

In 2018, a program was developed to address the Hawthorne effect and other shortcomings found in on-farm demonstrations. The Arkansas "most crop per drop" irrigation contest is a research and Extension program that promotes and documents the adoption of IWM practices. A total of 59 producers from 15 counties throughout the Arkansas Delta region participated in the contest in 2018 and 2019. The contest generated new data about crop-specific WUE $\left(\mathrm{kg}\right.$ ha- $\left.\mathrm{mm}^{-1}\right)$, crop yield $\left(\mathrm{kg} \mathrm{ha}^{-1}\right)$, and total water use $(\mathrm{mm})$. The winner in each crop category was the contestant with the greatest WUE. Each producer used at least one or more IWM tools (e.g., CHS, MIRI, soil moisture sensors, or surge irrigation).

Rules were developed for the contest, and a website was created to host contest information and entry forms. The contest rules were adapted from traditional yield contests (Arkansas Soybean Association, 2018; National Corn Growers, 2015; National Wheat Foundation, 2018). Unlike traditional yield contests, the Arkansas irrigation contest awards cash prizes to contestants with the greatest WUE, where WUE is defined as the crop yield divided by the total water received by the field. Total water is defined as precipitation plus irrigation. Precipitation was estimated from meteorological computer models, and irrigation volume was totalized with portable propeller flowmeters that were installed with tamper-proof safeguards. As in traditional yield contests, crop yield was supervised and witnessed by impartial observers, including Extension, USDA Natural Resource Conservation Service, and Conservation District employees.

Harvest yield estimates were determined in a manner similar to the California Rice Yield Contest, the National Corn Growers Association Yield Contest, the National Wheat 
Yield Contest, and the Arkansas "Go for the Green" Contest. Contestants harvested a minimum of $1.2 \mathrm{ha}$, from the top of the field to the bottom, and skipped two harvest machine widths between paths. A supervisor and a flowmeter were required for participation in the contest. University of Arkansas staff facilitated the contest, and a panel of irrigation experts served as judges to review and confirm the methods and final results.

\section{WATER USE EFFICIENCY}

Irmak et al. (2011) defined crop WUE as a benchmark metric:

$$
\mathrm{WUE}_{b}=Y_{i} /\left(P_{e}+I R+D S W\right)
$$

where

$\mathrm{WUE}_{b}=$ benchmark WUE (kg ha-mm-1 $)$

$Y_{i}=$ yield of irrigated crop $\left(\mathrm{kg} \mathrm{ha}^{-1}\right)$

$P_{e}=$ effective rainfall $(\mathrm{mm})$

$I R=$ irrigation applied $(\mathrm{mm})$

$\Delta S W=$ change in soil water content in the root zone during the growing season $(\mathrm{mm})$.

For the irrigation contest, this equation was used without considering $\triangle S W$. Because no accommodation was provided for soil type, the contribution of $\Delta \mathrm{SW}$ was ignored. High spring rainfall amounts are typical of the Arkansas climate; thus, it was assumed the soil water content was near field capacity during the first month of emergence. If the WUE values from the contest are used for other purposes, an adjustment to accommodate $\Delta S W$ would be needed to more closely estimate the actual WUE of the data collected in the contest.

A challenge in determining WUE is the difficulty in estimating effective precipitation $\left(P_{e}\right)$, i.e., the amount of rainfall that is stored by the soil after the excess leaves the field as runoff. The precipitation events for each contestant were carefully evaluated for magnitude and impact on the final results. There are dozens of published methods for estimating effective precipitation (Patwardhan et al., 1990; Ali and Mubarak, 2017), and they are all untested in the mid-south region. Rather than selecting a published method to estimate effective precipitation, $P_{e}$ was adjusted for only extreme events. In the first 30 days after emergence, any individual precipitation event was adjusted to $5 \mathrm{~cm}$ or less. Following 30 days after emergence, rainfall that exceed $7.62 \mathrm{~cm}$ was truncated to $7.62 \mathrm{~cm}$. Most furrow irrigation events are nearly $7.62 \mathrm{~cm}$, and this was the reasoning for using this $P_{e}$ value until crop maturity. There were only a few extreme events in excess of $7.62 \mathrm{~cm}$ in the two years of the contest, and the adjustment did not have any impact on the final ranking of the contestants. In the future, more work is needed to develop a regionally specific adjustment for effective precipitation.

\section{Meter Sealing}

Irrigation amounts were measured with portable, totalizing mechanical propeller flowmeters manufactured by McCrometer (Hemet, Cal.). Each flowmeter was sealed to the universal hydrant using circle lock clamps or horseshoe clamps (fig. 1). Serialized cable ties were used to secure the

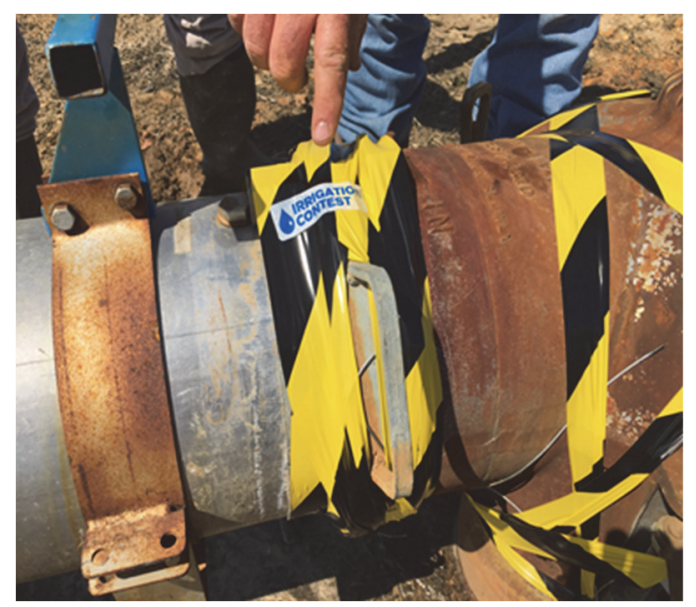

Figure 1. Sealing a flowmeter to prevent tampering with the measured irrigation amounts.

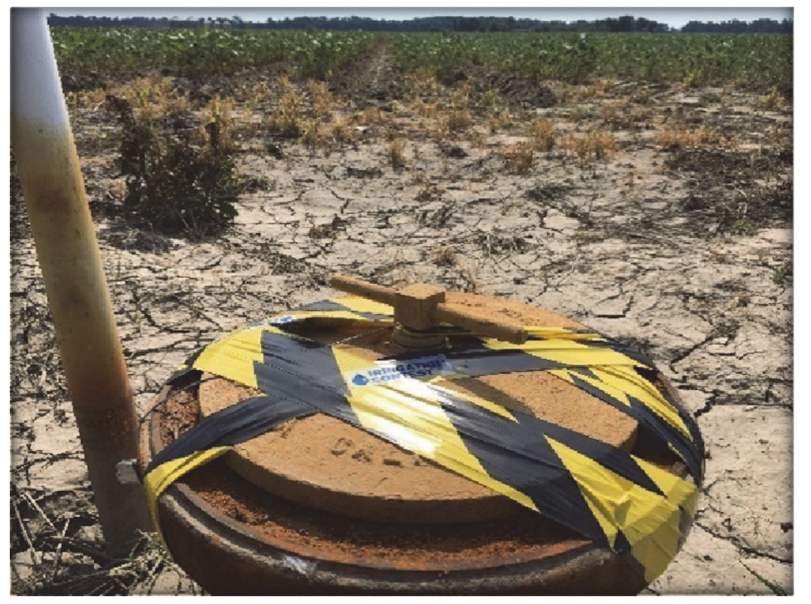

Figure 2. Sealing an alfalfa valve to prevent it from contributing additional irrigation water.

clamps and fittings. These cables could only be removed by cutting. The fitting connections were wrapped with poly pipe tape, and a unique identifying stamp was used across the tape lines. Universal hydrants were secured to the alfalfa valve and from the alfalfa valve to the flowmeter using the same procedure (fig. 1). Any additional fittings were also secured using this procedure to ensure that no additional irrigation water source contributed to the field (fig. 2).

Each contestant selected field of at least 12.1 ha size. The irrigation systems were required to have adequate straight-run pipe before the flowmeter impeller, but they could include vanes and flow straighteners when they met manufacture specifications and guidelines. The flowmeters were checked against a reference flowmeter and were required to test within $5 \%$. When a flowmeter failed to test within $5 \%$, the water use was adjusted according to the reference flowmeter.

\section{RAINFALL ESTIMATION}

FarmLogs (Ann Arbor, Mich.) and FieldView (Climate Corporation, San Francisco, Cal.) are computer-based services that provide rainfall estimates for user-defined areas. The rainfall amounts for each contest site, using the location data provided on the entry forms, were used to track rainfall 
contributions to the fields. The FarmLogs and FieldView estimates were compared to twelve publicly available rain gauges with continuous data throughout the irrigation season. An analysis was performed to determine if the measurements between weather station locations were different from the two computer model predictions. The model precipitation estimates were also used to eliminate maintenance issues associated with on-site rain gauges. The rainfall values were added to the total applied irrigation to determine the total water use. The modeled rainfall data may not be as accurate as a well-maintained weather station, but the bias was assumed to be equally distributed across all sites. Data from 18 weather stations were compared to the rainfall predictions generated by FarmLogs and FieldView during the 2018 and 2019 seasons. Using analysis of variance (ANOVA), no statistical difference was found between the rain gauges and the predicted datasets $(p=0.987)$.

FarmLogs and FieldView produced similar results when compared to private and publicly maintained tipping-bucket rain gauges. An absolute match was not necessary for data accuracy because it was more important to collect rainfall information for every location with one method, but these two programs were checked against each other for consistency. In addition, accumulated seasonal rainfall was considered more important for the contest than single-event accuracy. Rainfall was reported for each contest field for the period from emergence to maturity using planting dates provided on the entry forms and the estimated crop maturity date determined from seed supplier information.

\section{HARVEST YiELd ESTIMATE}

The supervisors were encouraged to help the contestants with irrigation decision-making during the season. Harvest operations were witnessed by supervisors or University of Arkansas staff. Before harvest, the combine grain hopper, grain cart, and truck hoppers were inspected and verified to be empty. The supervisor witnessed the full and tare weighing of the harvest truck. Crop yields were adjusted to $12 \%$ moisture for rice, $13.5 \%$ for soybeans, and $15 \%$ for maize. Foreign matter in excess of $1 \%$ was deducted from the yield. The winning contestants were required to provide a yield map of the entire field to confirm that the entire field was irrigated the same as the contest area. The contest area was measured and certified by a supervisor. Harvest passes from the top to the bottom of the field were required after turn row removal.

Arbitrary minimum yields were $12,572 \mathrm{~kg} \mathrm{ha}^{-1}$ for corn, $9,092 \mathrm{~kg} \mathrm{ha}^{-1}$ for rice, and 4,041 $\mathrm{kg} \mathrm{ha}^{-1}$ for soybeans. Thus, the contestants had to achieve a commercially acceptable yield and a high WUE to win. As the contest developed, the judging panel used past year results to further justify a fair minimum yield.

\section{CONTESTANT REPORT CARD}

Each contestant received a report card (fig. 3) showing the yield and WUE that the contestant achieved relative to the other contestants. This report card has been an important feedback mechanism. Two of the winners in 2019 who participated in 2018 indicated that their rankings on the report card incentivized them to improve their management in
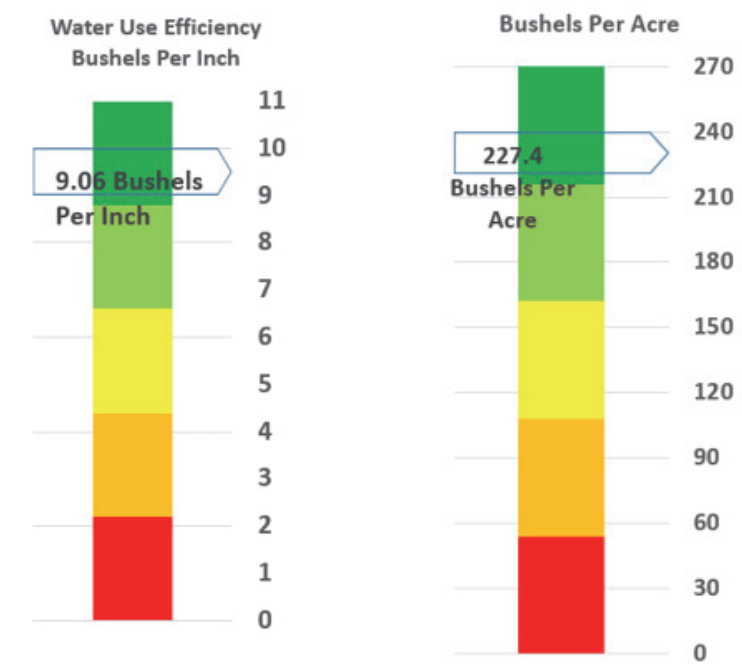

Figure 3. Example report card provided to each contestant, showing how the contestant ranked among peers in yield and WUE. This example uses the inch/bushel/acre units that U.S. producers are accustomed to and is only for illustrative purposes.

2019. In production agriculture, there are few opportunities for growers to gauge their management practices and acumen. The report card allowed irrigators to compare their IWM performance and productivity with their peers.

\section{DESCRIPTION OF AWARDS}

Winning contestants were recognized for achieving the greatest WUE in each crop category (corn, soybean, and rice). In 2018, only first place awards were given. In 2019, additional funding and sponsorship allowed two awards in rice and three in corn and soybeans. Additional support for the program has been provided by McCrometer through a discount program to provide flowmeters for the contest in addition to awarding flowmeters to the first-place winners. Annually, over $\$ 60,000$ in cash and products are distributed to contest winners at a state conservation conference. The conference is well attended by farmers and is well supported by the irrigation industry. Sponsors also use the conference as an opportunity to display the donated equipment and award it to the contest winners.

\section{RESULTS AND DISCUSSION}

The contest results were presented to a panel of three judges, who were experts in the field of irrigation, to review the technical methods used to determine the rankings. The panel reviewed and reaffirmed the rankings and could then propose rule changes for the next season.

In 2015, an irrigation survey of the mid-south region documented adoption of IWM practices (Henry et al., 2020). In $2015,40 \%$ of irrigators had adopted CHS on 111,289 ha in the region. In Arkansas, $66 \%$ of irrigators reported adopting CHS on at least one field. Surge irrigation was only used on $4 \%$ of furrow-irrigated fields in Arkansas and on 6\% of furrow-irrigated fields in the four-state mid-south region. About $24 \%$ of irrigators in the region used soil moisture sensors, but only $9 \%$ of irrigators in Arkansas reported using sensors. MIRI was practiced on 88,013 ha, with $55 \%$ of irrigators reporting. 
On their entry forms, contestants indicated which IWM tools they used on the contest field. All (100\%) of the contestants used CHS (e.g., Pipe Planner, PHAUCET, or the Rice Irrigation app), 32\% used surge irrigation, and 55\% used soil moisture sensors to manage irrigation on their contest fields. Of the flooded rice entries, four used AWD, which included MIRI, and two used MIRI (without AWD). No entrant used cascade-flooding (without AWD or MIRI). Of the 19 rice entries, 13 used the furrow-irrigated rice (FIR) method. All corn and soybean fields were furrow-irrigated.

Adoption of IWM practices, such as surge and soil moisture monitoring, is very low in the region, but the contestants reported much higher adoption of all four of the IWM practices. We did not expect that so many contestants would use FIR. Conventional flooding and MIRI of rice are much more common practices. Only about $12 \%$ of the rice area is FIR, and FIR is considered an emerging and still developing irrigation method. Many contestants reported that the contest provided motivation to try new technology or management practices to improve their irrigation, and that they plan to use what they learned from managing their contest field on the rest of their farming operation.

Table 1 shows the rough rice yields, rainfall, irrigation water use, total water, and WUE for the rice category of the contest in 2018 and 2019. The highest yields did not have the highest WUE. In both years, the winning entry was an AWD field. In 2019, the highest WUE was achieved with FIR; however, because the field did not meet the minimum yield, it was disqualified. In 2018, the highest yield was $13,448 \mathrm{~kg} \mathrm{ha}^{-1}$, achieved with FIR. This yield is considered exceptional, but the field received considerable rainfall and irrigation additions that resulted in a poor WUE. We believe there should be a yield difference between AWD and FIR. In 2018, there were four AWD fields and six FIR fields, with no significant difference in yields between AWD and FIR ( $p$ $=0.31)$ or total water use $(p=0.33)$. Generally, it is believed that yields are less and water use is greater with FIR, but the results of the contest did not support this general belief.

Table 1. Contest results for rice category (2018-2019).

\begin{tabular}{|c|c|c|c|c|c|}
\hline $\begin{array}{c}\text { Year and } \\
\text { Irrigation } \\
\text { Method }\end{array}$ & $\begin{array}{c}\text { Yield } \\
\left(\mathrm{kg} \mathrm{ha}^{-1}\right)\end{array}$ & $\begin{array}{c}\text { Rainfall } \\
(\mathrm{mm})\end{array}$ & $\begin{array}{c}\text { Irrigation } \\
(\mathrm{mm})\end{array}$ & $\begin{array}{l}\text { Total } \\
\text { Water } \\
(\mathrm{mm})\end{array}$ & 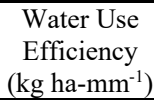 \\
\hline \multicolumn{6}{|l|}{2018} \\
\hline AWD & 11,550 & 340 & 406 & 746 & 15.5 \\
\hline AWD & 11,151 & 338 & 516 & 854 & 13.1 \\
\hline FIR & 9,786 & 320 & 483 & 802 & 12.2 \\
\hline FIR & 11,470 & 362 & 665 & 1,027 & 11.2 \\
\hline AWD & 11,038 & 389 & 646 & 1,035 & 10.7 \\
\hline FIR & 9,634 & 371 & 541 & 912 & 10.6 \\
\hline MIRI & 10,535 & 347 & 516 & 1,102 & 9.6 \\
\hline FIR & 10,195 & 187 & 827 & 1,014 & 10.1 \\
\hline FIR & 13,448 & 406 & 1,216 & 1,622 & 8.3 \\
\hline Flood & 11,253 & 347 & 1,012 & 1,359 & 8.3 \\
\hline FIR & 9,714 & 372 & 931 & 1,303 & 7.5 \\
\hline FIR & 6,652 & 383 & 796 & 1,180 & 5.6 \\
\hline \multicolumn{6}{|l|}{2019} \\
\hline FIR & 8,745 & 498 & 67 & 564 & 15.5 \\
\hline AWD & 10,501 & 391 & 339 & 730 & 14.4 \\
\hline FIR & 10,091 & 379 & 574 & 953 & 10.6 \\
\hline FIR & 10,585 & 474 & 617 & 1,091 & 9.7 \\
\hline FIR & 8,964 & 382 & 604 & 986 & 9.1 \\
\hline FIR & 9,817 & 461 & 774 & 1,235 & 8.0 \\
\hline FIR & 9,609 & 636 & 602 & 1,238 & 7.8 \\
\hline FIR & 8,211 & 689 & 475 & 1,164 & 7.1 \\
\hline
\end{tabular}

All corn entries were furrow-irrigated during 2018 and 2019 (table 2). As in the rice category of the contest, the highest yields did not result in the highest WUE. In Arkansas, corn can be planted as early as February through May and thus is growing when there is often frequent precipitation, so irrigation may not be needed during the season. The high rainfall experienced by some farmers reduced their WUE; thus, irrigators who did not receive too much rain and adequately managed irrigation performed well in the contest. Winners of the contest in 2018 and 2019 both used CHS, surge irrigation, and soil moisture sensors, supporting the findings of Spencer et al. (2019).

All soybean entries were furrow-irrigated in 2018 and 2019 (table 3). Unlike the rice and corn categories, the highest yields also resulted in the highest WUE. While other entries had less total water, the main driver for high WUE was yield, as shown in table 3. All entries used CHS, none used surge irrigation, and some used soil moisture sensors. The winner in 2018 did not use soil moisture sensors but had experience with them from neighboring fields. The winner in 2019 used CHS and soil moisture sensors and indicated that, as a result of using soil moisture sensors for the first time in the contest, he planned to adopt the technology on his farm.

The contest provided yield, irrigation water use, and rainfall data to compare across the three major crops in the region. The contest results will provide historical data on WUE for the region that will be helpful in understanding and documenting the impact of conservation efforts in the region.

The irrigation contest created many success stories. Two of the 2019 contest winners who participated in 2018 saw many improvements as a result of using IWM tools and placed well in the 2019 contest. Many of the contestants stated that adoption of IWM tools, such as Watermark sensors, takes time, especially in the first year, until trust is established. Winners have had the opportunity to discuss their success at conferences and other Extension programs. Peer-to-peer discussions about using IWM to win a contest can be a powerful motivator for others who are unsure about such unfamiliar practices. The contest results are summarized annually in reports and published on-line (www.uaex.edu/irrigation).

Table 2. Contest results for maize category (2018-2019).

\begin{tabular}{cccccc}
\hline Year & $\begin{array}{c}\text { Yield } \\
\left(\mathrm{kg} \mathrm{ha}^{-1}\right)\end{array}$ & $\begin{array}{c}\text { Rainfall } \\
(\mathrm{mm})\end{array}$ & $\begin{array}{c}\text { Irrigation } \\
(\mathrm{mm})\end{array}$ & $\begin{array}{c}\text { Total } \\
\text { Water } \\
(\mathrm{mm})\end{array}$ & $\begin{array}{c}\text { Water Use } \\
\text { Efficiency } \\
\left(\mathrm{kg} \mathrm{ha-mm}^{-1}\right)\end{array}$ \\
\hline 2018 & 13,309 & 320 & 107 & 426 & 31.2 \\
& 11,496 & 327 & 73 & 400 & 28.7 \\
& 14,241 & 331 & 215 & 546 & 26.1 \\
& 13,706 & 254 & 273 & 527 & 26.0 \\
& 13,229 & 229 & 287 & 516 & 25.6 \\
& 13,282 & 294 & 255 & 549 & 24.2 \\
& 13,611 & 281 & 306 & 587 & 23.2 \\
& 16,626 & 314 & 429 & 743 & 22.4 \\
& 10,043 & 299 & 349 & 648 & 15.5 \\
\hline 13,940 & 458 & 38 & 496 & 28.1 \\
& 15,527 & 559 & - & 559 & 27.8 \\
& 15,896 & 493 & 126 & 619 & 25.7 \\
& 16,348 & 600 & 139 & 740 & 22.1 \\
& 12,695 & 540 & 83 & 624 & 20.4 \\
& 17,566 & 767 & 109 & 876 & 20.1 \\
& 17,408 & 767 & 109 & 876 & 19.9 \\
& 13,868 & 657 & 77 & 733 & 18.9 \\
15,259 & 668 & 151 & 819 & 18.6 \\
& 15,038 & 622 & 364 & 986 & 15.3 \\
11,227 & 828 & 281 & 1,109 & 10.1 \\
\hline
\end{tabular}


Table 3. Contest results for soybean category (2018-2019).

\begin{tabular}{|c|c|c|c|c|c|}
\hline Year & $\begin{array}{c}\text { Yield } \\
\left(\mathrm{kg} \mathrm{ha}^{-1}\right)\end{array}$ & $\begin{array}{c}\text { Rainfall } \\
(\mathrm{mm})\end{array}$ & $\begin{array}{c}\text { Irrigation } \\
(\mathrm{mm})\end{array}$ & $\begin{array}{l}\text { Total } \\
\text { Water } \\
(\mathrm{mm}) \\
\end{array}$ & 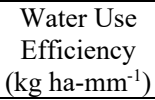 \\
\hline \multirow[t]{12}{*}{2018} & 6,465 & 406 & 261 & 667 & 9.7 \\
\hline & 4,018 & 294 & 195 & 489 & 8.2 \\
\hline & 5,331 & 447 & 251 & 697 & 7.6 \\
\hline & 5,354 & 406 & 315 & 720 & 7.4 \\
\hline & 3,694 & 380 & 124 & 504 & 7.3 \\
\hline & 4,544 & 419 & 203 & 622 & 7.3 \\
\hline & 4,077 & 379 & 227 & 606 & 6.7 \\
\hline & 3,334 & 358 & 142 & 500 & 6.7 \\
\hline & 4,110 & 358 & 267 & 625 & 6.6 \\
\hline & 4,571 & 433 & 320 & 752 & 6.1 \\
\hline & 4,243 & 356 & 389 & 745 & 5.7 \\
\hline & 4,303 & 335 & 442 & 777 & 5.5 \\
\hline \multirow[t]{15}{*}{2019} & 7,061 & 497 & 166 & 664 & 10.6 \\
\hline & 6,952 & 497 & 166 & 664 & 10.5 \\
\hline & 5,520 & 488 & 96 & 583 & 9.5 \\
\hline & 4,576 & 436 & 97 & 533 & 8.6 \\
\hline & 4,603 & 389 & 156 & 545 & 8.4 \\
\hline & 5,246 & 530 & 108 & 638 & 8.2 \\
\hline & 4,486 & 512 & 50 & 562 & 8.0 \\
\hline & 3,966 & 385 & 151 & 536 & 7.4 \\
\hline & 5,246 & 530 & 222 & 752 & 7.0 \\
\hline & 3,921 & 410 & 220 & 630 & 6.2 \\
\hline & 2,911 & 415 & 90 & 504 & 5.8 \\
\hline & 4,701 & 773 & 95 & 868 & 5.4 \\
\hline & 5,246 & 530 & 442 & 972 & 5.4 \\
\hline & 4,205 & 550 & 332 & 882 & 4.8 \\
\hline & 3,911 & 668 & 213 & 881 & 4.4 \\
\hline
\end{tabular}

\section{CONCLUSIONS}

The Arkansas "most crop per drop" irrigation contest is a novel approach to promoting awareness and adoption of IWM practices. While there is a monetary prize, the feedback provided to each of the contestants on how they compare to their peers gives the contestants a benchmark for improving their water management skills. The contest also documents regional cropping system WUE data, which can be used to better understand the long-term profitability of irrigators in the region. Adoption of IWM practices has been higher for those who participated in the contest than their Arkansas peer average, with documented adoption increases of $33 \%$ for computerized hole selection, $28 \%$ for surge irrigation, and $51 \%$ for soil moisture monitoring. All rice contestants used MIRI (and 66\% of those used AWD) compared to the $55 \%$ of Arkansas irrigators who reported using MIRI. The impact and synergy of using various water management technologies were also quantified in this program. The program revealed that FIR yields and water use are very similar to AWD and MIRI yields. Generally, the highest yields did not result in winning the contest in the maize and rice categories but did in the soybean category. We believe that the contest report card is a key feedback tool that motivates contestants to improve IWM on their farms, so every irrigator who enters the contest is a winner.

\section{ACKNOWLEDGEMENTS}

The material is based on work that is supported, in part, by the USDA Natural Resource Conservation Service, the Arkansas Corn and Grain Sorghum Board, the Arkansas Soybean Promotion Board, RiceTec, Mars Corporation,
McCrometer, Seametrics, $\mathrm{P}$ and $\mathrm{R}$ Surge, ValmontAgSense, Trellis, Irrometer, Delta Plastics, and the USDA National Institute of Food and Agriculture (Project No. ARK02591).

\section{REFERENCES}

Ali, M. H., \& Mubarak, S. (2017). Effective rainfall calculation methods for field crops: An overview, analysis, and new formulation. Asian Res. J. Agric., 7(1), article 36812. https://doi.org/10.9734/ARJA/2017/36812

Arkansas Soybean Association. (2018). Grow for the green soybean yield challenge rules \& entry form. Little Rock: Arkansas Soybean Association.

Bryant, C. J., Krutz, L. J., Falconer, L., Irby, J. T., Henry, C. G., Pringle III, H. C., ... Wood, C. W. (2017). Irrigation water management practices that reduce water requirements for midsouth furrow-irrigated soybean. Crop Forage Turfgrass Mgmt., 3(1). https://doi.org/10.2134/cftm2017.04.0025

Henry, C. G., Henggeler, J., Krutz, L. J., \& Levy, R. (2020). MidSouth irrigation survey. Unpublished.

Henry, C. G., Hirsh, S. L., Anders, M. M., Vories, E. D., Reba, M. L., Watkins, K. B., \& Hardke, J. T. (2016). Annual irrigation water use for Arkansas rice production. J. Irrig. Drain. Eng., 142(11), article 05016006. https://doi.org/10.1061/(ASCE)IR.1943-4774.0001068

Irmak, S., Odhiambo, L. O., Kranz, W. L., \& Eisenhauer, D. E. (2011). Irrigation efficiency and uniformity, and crop water use efficiency. Extension circular EC732. Lincoln, NE: University of Nebraska, Department of Biological Systems Engineering.

National Corn Growers Association. (2015). National corn yield contest: Entry and harvest rules. Chesterfield, MO: National Corn Growers Association. Retrieved from https://membership.ncga.com/Mobile/Shared/EntryHarvestRul es2015a.pdf

National Wheat Foundation. (2018). National wheat yield contest. Washington, DC: National Wheat Foundation. Retrieved from https://wheatfoundation.org/rules-and-registration/

Patwardhan, A. S., Nieber, J. L., \& Johns, E. L. (1990). Effective rainfall estimation methods. J. Irrig. Drain. Eng., 116(2), 182193.

Roethlisberger, F. J. (1941). Management and morale. Cambridge, MA: Harvard University Press.

Spencer, G. D., Krutz, L. J., Falconer, L. L., Henry, W. B., Henry, C. G., Larson, E. J., ... Atwill, R. L. (2019). Irrigation water management technologies for furrow-irrigated corn that decrease water use and improve yield and on-farm profitability. Crop Forage Turfgrass Mgmt., 5(1), 180100. https://doi.org/10.2134/cftm2018.12.0100

UA Irrigation Water Management Team. (2016). Rice irrigation. Mobile application. Fayetteville, AR: University of Arkansas, Rice Research and Extension Center. Retrieved from https://play.google.com/store/apps/details?id=org.uark.riceirrigat ion

UA Irrigation Water Management Team. (2017). Rice irrigation. Mobile application. Fayetteville, AR: University of Arkansas, Rice Research and Extension Center. Retrieved from http://itunes.apple.com

Vories, E. D., Tacker, P. L., \& Hogan, R. (2005). Multiple inlet approach to reduce water requirements for rice production. Appl. Eng. Agric., 21(4), 611-616. https://doi.org/10.13031/2013.18571 